\title{
GASTRIC ANTRAL VASCULAR ECTASIA PRESENTING WITH SEVERE AMEMIA-A CASE REPORT
}

\author{
MOHAMMAD AL-AMIN ${ }^{1}$, SHANTA ROY ${ }^{2}$, SWADESH BARMAN $^{2}$, SHAHIDUL ISLAM $^{2}$, HUMAYARA TABASSUM $^{2}$, \\ AHMEDUL KABIR 3
}

\begin{abstract}
Iron deficiency anemia secondary to gastrointestinal bleeding is very common in the elderly. Gastric antral vascular ectasia is an uncommon cause of gastrointestinal bleeding. It is more common in females than males, and manifests mostly as iron deficiency anemia due to the gradual blood loss. There are two types-the classic type and the diffuse type. The appearance of the classic type earns it the name watermelon stomach. Pathogenesis is unknown though several humoral factors have been proposed. Diagnosis is based on the clinical history and endoscopic appearance and histological changes. The lesions are treated by endoscopic methods, the most commonly used modalities are heater probe, electrocoagulation, Argon photocoagulation and laser. Response rates depend on methods used, and the classic type responds better than the diffuse type. We presented a 60 years old lady presented with unexplained severe anaemia requiring repeated blood transfusion and ultimately diagnosed as a case of GAVE.
\end{abstract}

Keywords: Gastric antral vascular Ectasia, Haematemesis, Anemia

\section{Introduction}

Gastric antral vascular ectasia (GAVE) syndrome, also known as watermelon stomach, is a rare but significant cause of severe acute or chronic gastrointestinal blood loss in the elderly. ${ }^{1-4}$ Although it is associated with heterogeneous medical conditions, including hepatic, renal, and cardiac diseases, its pathogenesis is unknown. ${ }^{1-3}$ The diagnosis of GAVE syndrome in patients with renal or hepatic disease is often problematic because there are more frequent causes of gastrointestinal bleeding in these diseases (vascular malformations, peptic ulcer disease, esophageal or gastric varices, and colonic and rectal ulcers) that overshadow GAVE syndrome. Furthermore, diagnosis may be challenging because gastrointestinal bleeding may be occult or overt, and the endoscopic appearance of GAVE syndrome resembles that in portal hypertensive gastropathy (PHG) or antral gastritis. However, differentiation of GAVE syndrome from these other causes is critical because of the vastly disparate therapies required for each. Building on a leading theory that mechanical stress is involved in the pathogenesis, we speculate that the diverse medical risk factors may be related to GAVE syndrome through an autonomic dysfunction. ${ }^{5,6}$

\section{Case Report}

A woman, age 70 years, with chronic kidney disease secondary to diabetes and hypertension presented
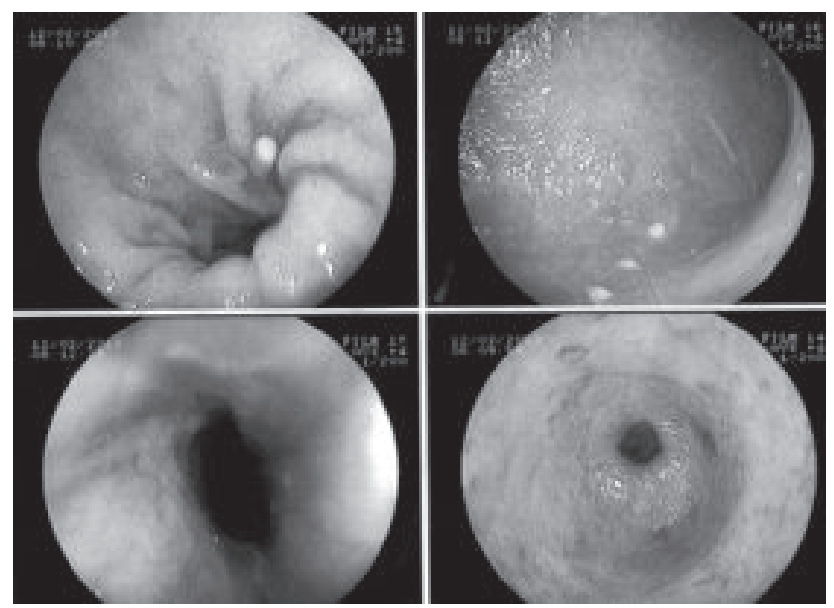

at our institution and reported several weeks of intermittent generalized abdominal pain and vomiting and daily minimal stools that appeared blood-streaked on wiping but without hematemesis or melena. Laboratory findings showed a hemoglobin of $10.5 \mathrm{~g} /$ $\mathrm{dL}$ (after getting 3 unit BT); a hematocrit of 30.3\%; and normal hepatic function, platelet count, prothrombin time, and international normalized ratio. Although the anemia was consistent with iron deficiency, the low hemoglobin level invariably decreased to pretransfusion levels within days of blood transfusion. Ultrasonography of the abdomen revealed spleenomegaly but no other significant

\footnotetext{
1. Registrar, Dhaka Medical College

2. Honarary Medical officer, Dhaka medical college,

3. Associate professor, Dhaka medical college
} 
gastrointestinal pathology. There were no other cause of anaemia. Instead, a endoscopy revealed extensive vascular ectasias and patchy erythema in the distal antrum that were diagnostic of GAVE syndrome, but no esophageal or gastric varices. GAVE syndrome was considered as plausible cause of severe anemia from gastrointestinal blood loss. The endoscopist considered primary medical therapy with laser photocoagulation but because of financial crisis patient refused treatment.

\section{Discussion:}

Gastric antral vascular ectasia syndrome is a rare entity. It is present in 3\% of cirrhotics, whereas 30$40 \%$ of GAVE patients have portal hypertension. Classic noncirrhotic patient is middle-aged female with autoimmune disease or atrophic gastritis. ${ }^{7}$ Its association with scleroderma, pernicious anaemia, chronic renal failure, aortic stenosis, gastric carcinoma, bone marrow transplantation, Addison's disease and antral mucosal prolapse is reported in the world literature ${ }^{8-10}$.

It is characterized by chronic gastrointestinal blood loss, iron deficiency anaemia and transfusion dependency. Very rarely, it may present as acute bleeding. Endoscopic appearances are classically described as watermelon stomach prominent longitudinal red stripes on antral mucosa radiating out from pylorus. Each stripe represents multiple flat red mucosal lesions of 1 to $5 \mathrm{~mm}$ size, lying in close proximity. ${ }^{7}$ Differentiation from portal hypertensive gastropathy is by 1) antrum as predominant site, 2) lack of snake-skin-like appearance, 3) dilated capillaries with thrombi, fibrohylinosis and spindle cell proliferation in biopsy, 4) no relation to degree of portal hypertension and 5) no response to betablockers and portosystemic shunts. Pathogenesis of GAVE is unclear - mucosal atrophy, high gastrin levels, hypertrophy of neuroendocrine cells in antrum (5-HT and VIP), mechanical stress and portal hypertension are implicated. ${ }^{8}$ Treatment of GAVE is difficult. Medical treatments like steroids, estrogenprogesterone combination and tranexamic acid are tried with inconsistent results. Endoscopic treatment with laser photocoagulation (Nd-Yag or APC) or heat probe diathermy is increasingly reported to be successful and can delay surgical antrectomy, which is definite curative treatment $\mathrm{t}^{9,11,12}$.
As in Bangladesh Iron deficiency anaemia is common, we have to exclude many causes. It is very important to keep in mind the possibility of GAVE and everyone with unexplained anaemia should have endoscopy of upper GIT to exclude GI bleeding possibilities.

\section{References}

1. R ider JA, Klotz AP, Kirshner JB. Gastritis with venocapillary ectasia as a source of massive gastric hemorrhage. Gastroenterology 1953 May;24(1):118-23.

2. Selinger CP, Ang YS. Gastric antral vascular ectasia (GAVE): an update on clinical presentation, pathophysiology and treatment. Digestion 2008;77(2):131-7.

3. Stefandis I, Liakopoulos V, Kapsoritakis AN, et al. Gastric antral vascular ectasia (watermelon stomach) in patients with ESRD. Am J Kidney Dis 2006 Jun;47(6):e77-82.

4. N ovitsky YW, Kercher KW, Czerniach DR, Litwin DE. Watermelon stomach: pathophysiology, diagnosis, and management. J Gastrointest Surg 2003 JulAug;7(5):652-61.

5. Quintero E, Pique JM, Bombi JA, et al. Gastric mucosal vascular ectasias causing bleeding in cirrhosis. A distinct entity associated with hypergastrinemia and low serum levels of pepsinogen I. Gastroenterology 1987 Nov;93(5): 1054-61.

6. C harneau J, Petit R, Calès P, Dauver A, Boyer J. Antral motility in patients with cirrhosis with or without gastric antral vascular ectasias. Gut 1995 Oct;37(4):488-92.F

7. Chapman RW, Peter WA. Effect of liver disease on gastrointestinal tract. In: Oxford Textbook of Clinical hepatology, second ed. UK : Oxford University Press. 1999:1817-22.

8. Spahr L, Villeneure JP, Dufresne MP, Tasse D, et al. GAVE in cirrhotic patients - absence of relation with portal hypertension. Gut 1999;44:739-42.

9. Moss SF, Gosh P, Thomas DM, Jackson JE, et al. Gastric antral vascular ectasia in maintenance treatment with estrogen - progesterone. Gut 1992;33:715-7.

10. Gostout CJ, Viggiano TR, Ahlquist DA, et al. Clinical and endoscopic spectrum of the watermelon stomach. J Clin Gastroenterol 1992;15:256-63.

11. Gracia N, Sanyal AJ. Portal hypertensive gastropathy and endoscopic spectrum of the watermelon stomach. J Clin Gastroenterol 1992; 15: 256-63.

12. McCormick PA, Ooi H, Crosbie O. Tranexamic acid for severe bleeding gastric antral vascular ectasia in cirrhosis.Gut 1998;42:750-2. 